LA-UR-14-23853

Approved for public release; distribution is unlimited.

Title: Blue Room Vertical Flight Path

Author(s): $\quad$ Mocko, Michal

Intended for: $\quad$ To be shared with ESS collaborators (external to LANL).

Issued: $\quad$ 2014-05-30 


\section{Disclaimer:}

Los Alamos National Laboratory, an affirmative action/equal opportunity employer,is operated by the Los Alamos National Security, LLC for the National NuclearSecurity Administration of the U.S. Department of Energy under contract DE-AC52-06NA25396. By approving this article, the publisher recognizes that the U.S. Government retains nonexclusive, royalty-free license to publish or reproduce the published form of this contribution, or to allow others to do so, for U.S. Government purposes. Los Alamos National Laboratory requests that the publisher identify this article as work performed under the auspices of the U.S. Departmentof Energy. Los Alamos National Laboratory strongly supports academic freedom and a researcher's right to publish; as an institution, however, the Laboratory does not endorse the viewpoint of a publication or guarantee its technical correctness. 


\title{
Blue Room Vertical Flight Path
}

\author{
M. Mocko, LANSCE-LC
}

May 28, 2014 


\section{Vertical FP alignment with respect to proton} beam

Lowered plumb, string intersecting the laser beam which is aligned with the proton beam axis.
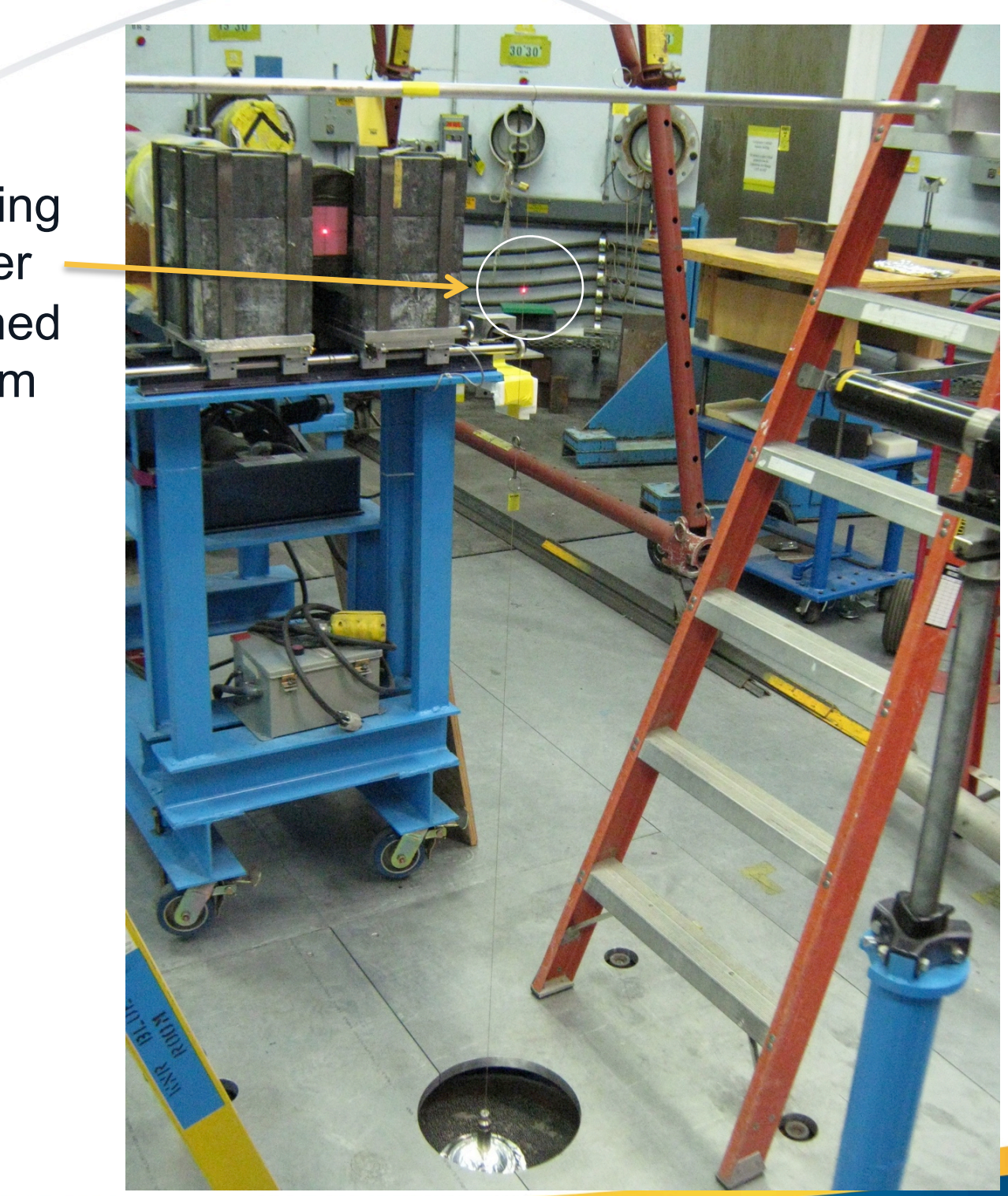


\section{Vertical FP alignment with respect to proton}

\section{beam}

Lase beam aligned on proton beam axis

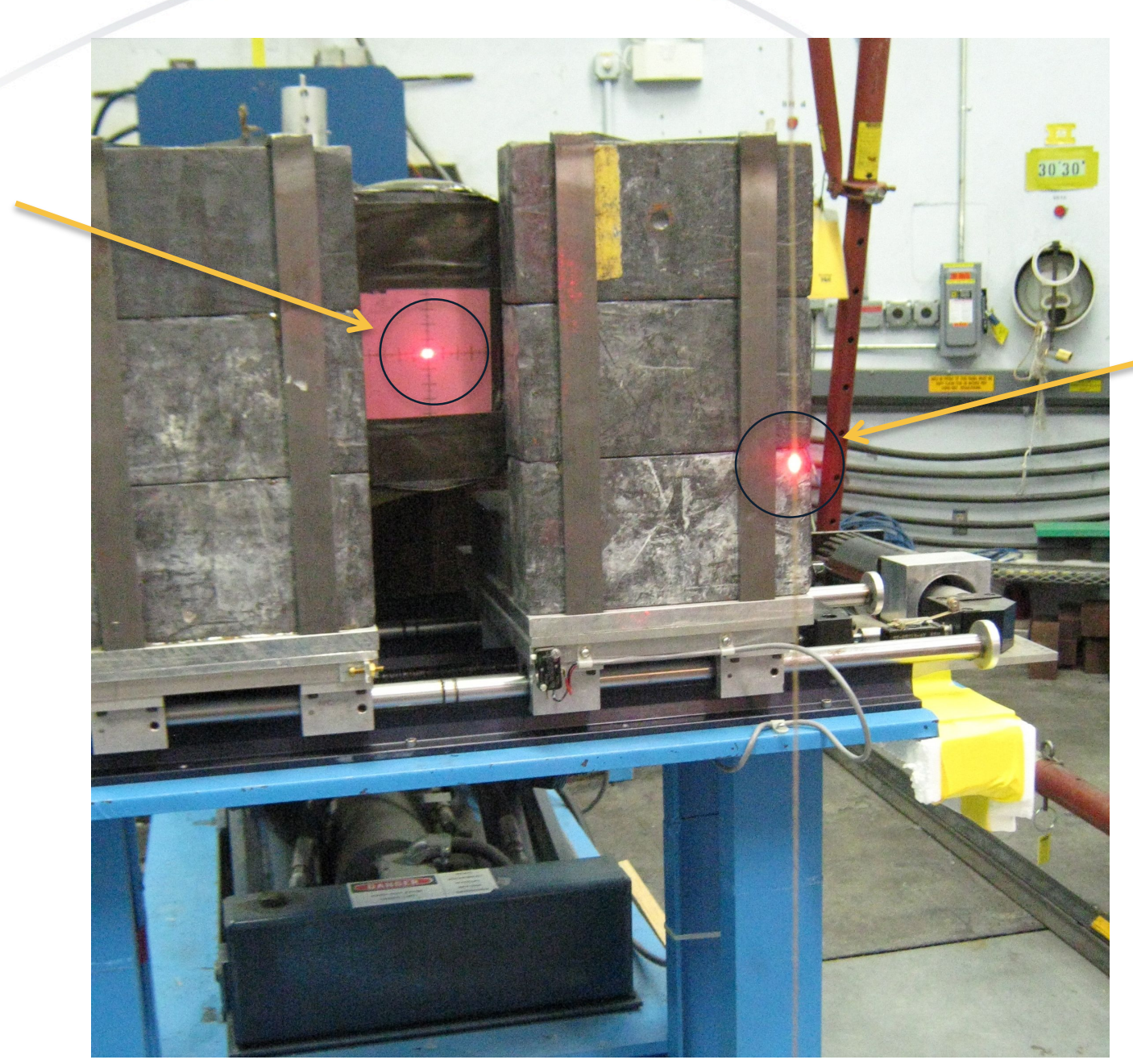

Laser beam intersecting the plumb string 


\section{Vertical FP alignment with respect to proton} beam
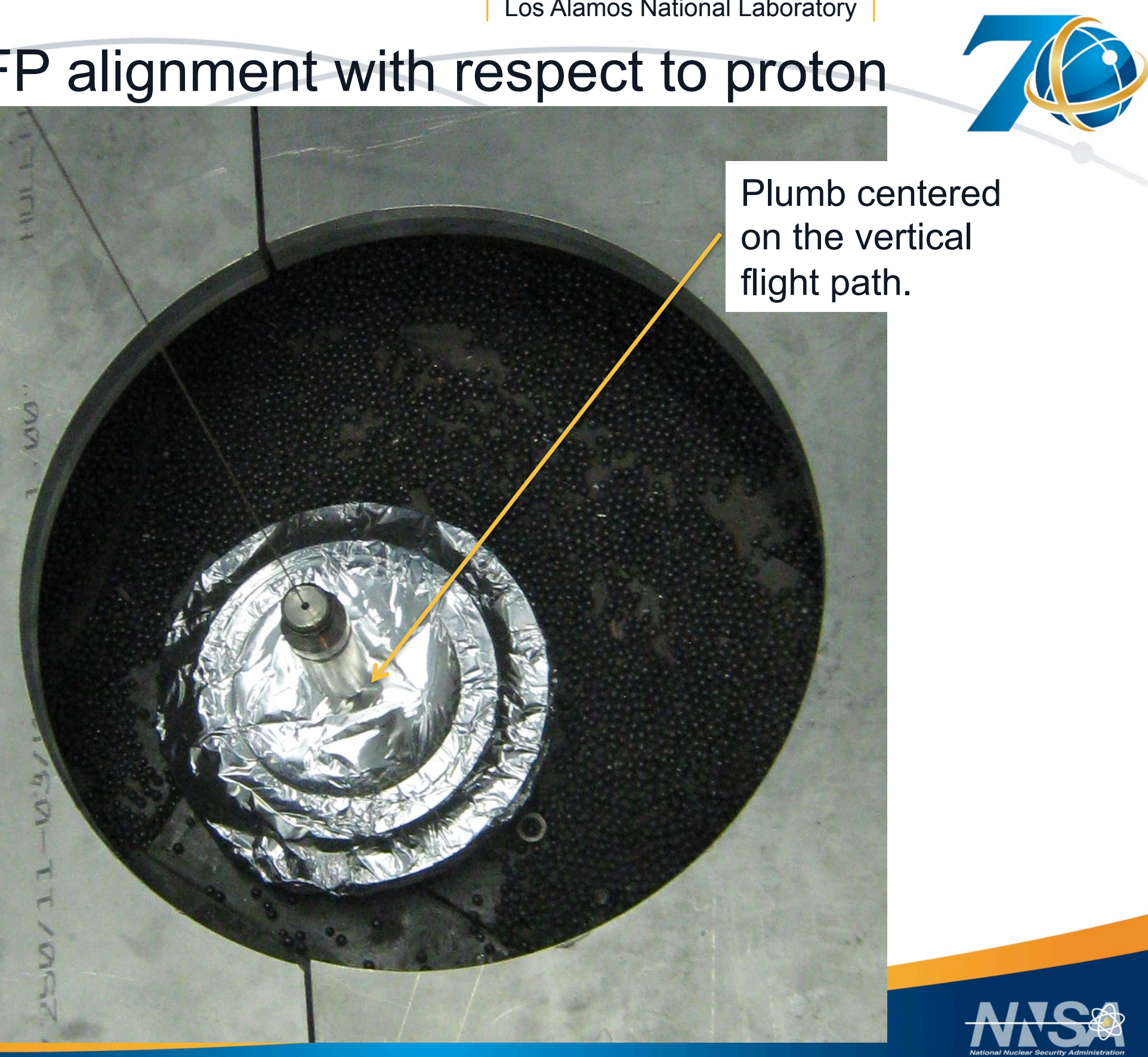


\section{Vertical FP alignment with respect to proton} beam

Vertical flight path is designed to be rotated. The inner flight path is approximately $2 \mathrm{~cm}$ off center.
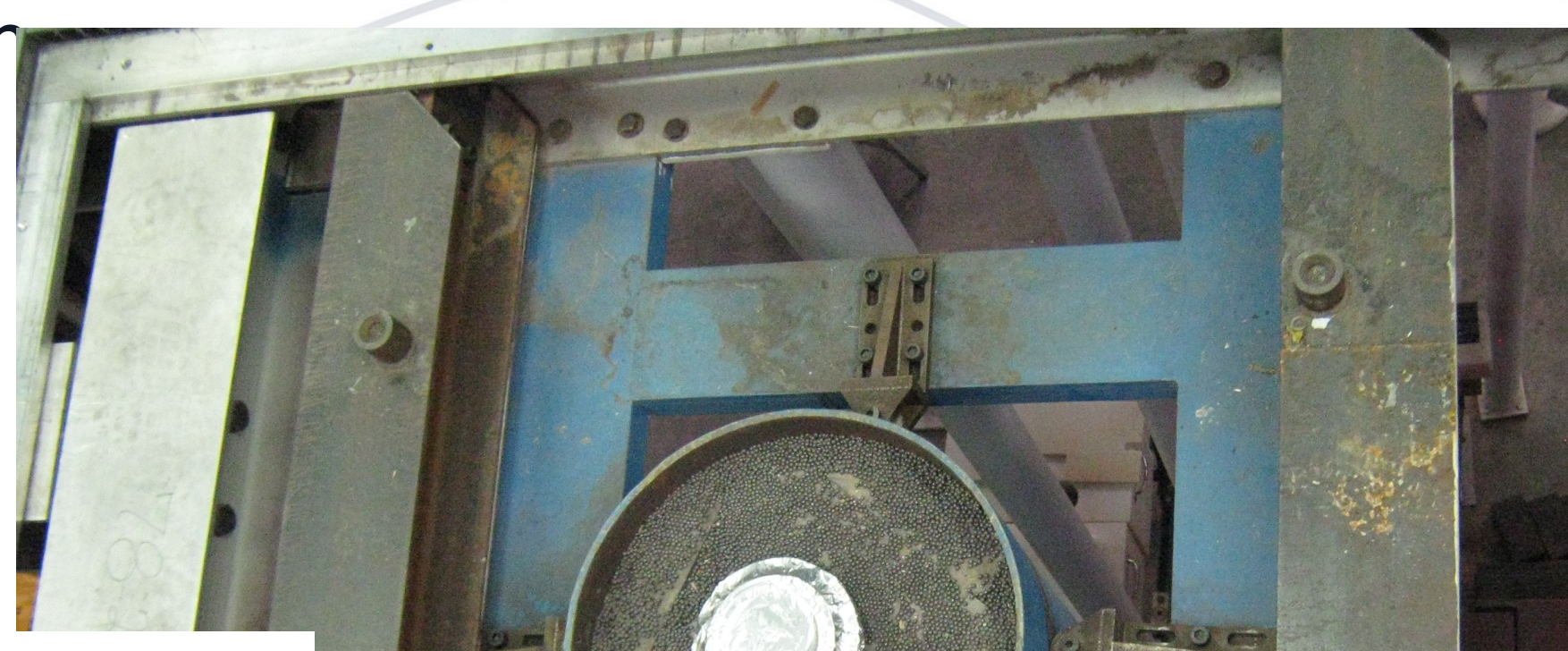


\section{Vertical FP alignment with respect to proton} beam

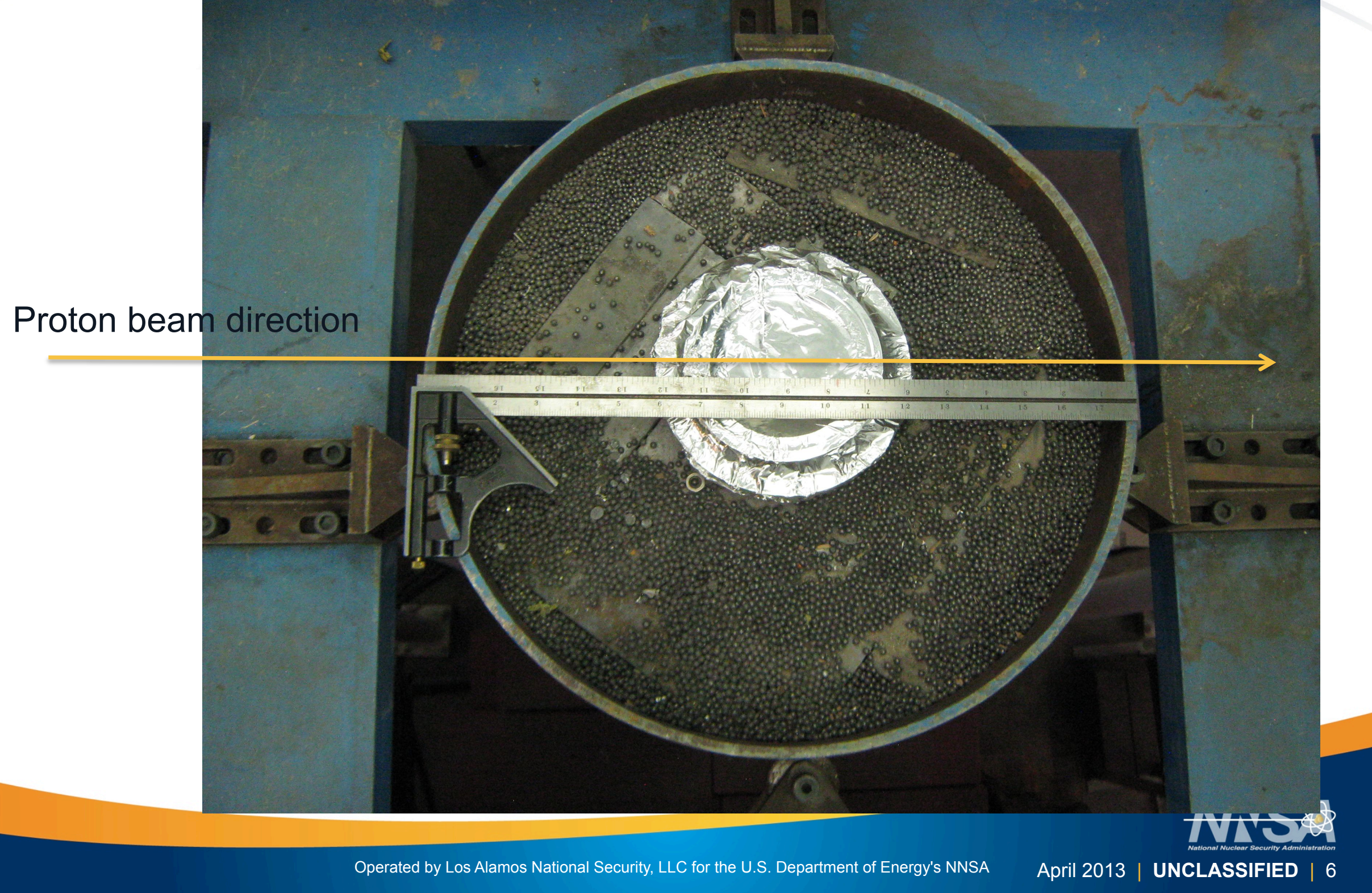




\section{Vertical FP alignment with respect to proton}

\section{beam}

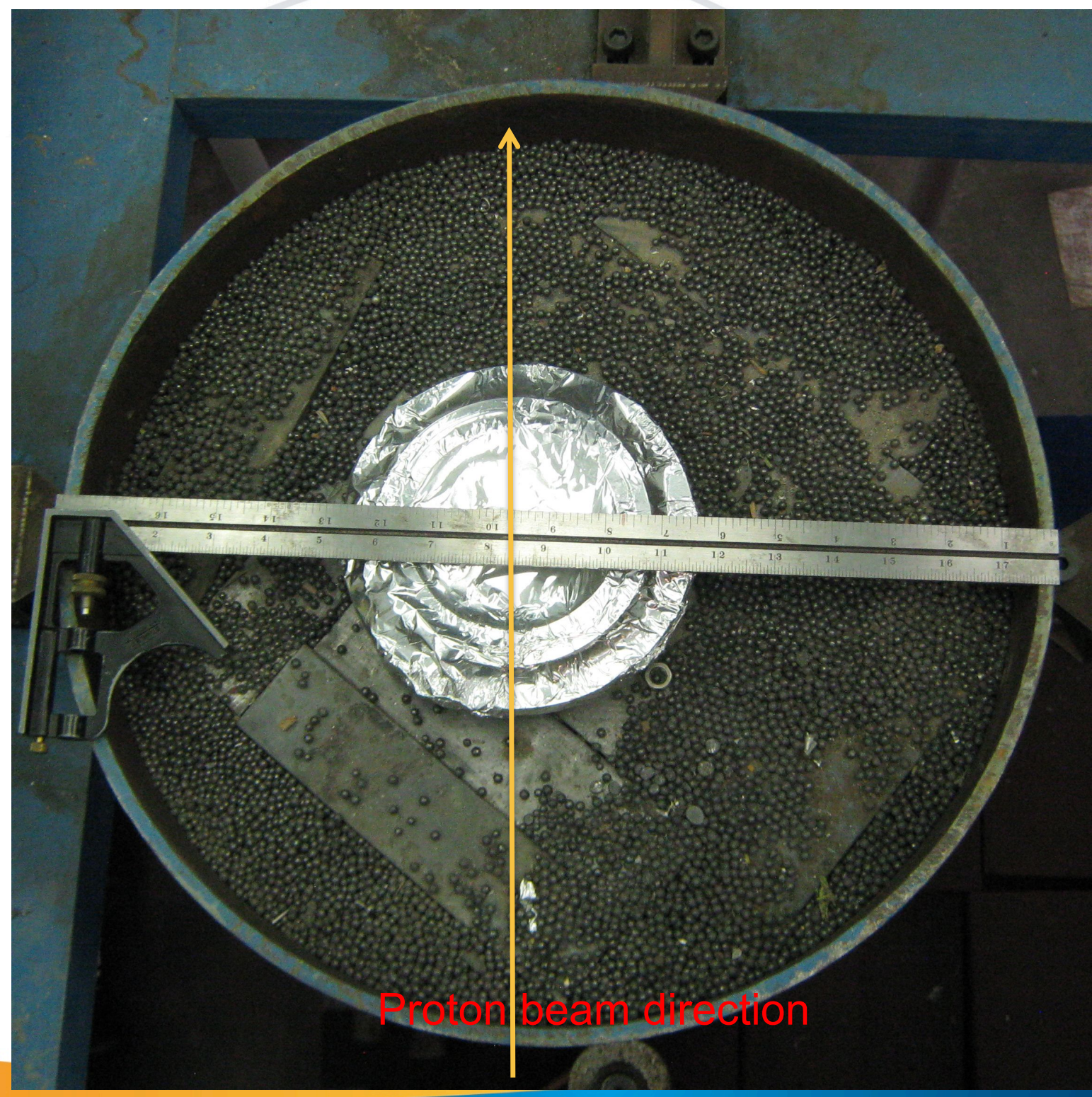

